\title{
Precision Investigation of the Number of Photographs Taking Station in Photogrammetric Evaluation for Non-metric Cameras
}

\author{
Ali Ulvi ${ }^{1, *}$, Murat Yakar ${ }^{2}$ \\ ${ }^{1}$ Hadim Vocational Schools of Higher Education, Selcuk University, Konya, Turkey \\ ${ }^{2}$ Department of Geomatic Engineering, Selcuk University, 42075 Konya, Turkey
}

Copyright $\bigcirc 2016$ by authors, all rights reserved. Authors agree that this article remains permanently open access under the terms of the Creative Commons Attribution License 4.0 International License

\begin{abstract}
In this study, the effect of number of picture taking on precision was investigated and non-metric digital camera was used. In the study, triplet convergent picture taking and sestet convergent picture taking were compared. As a result of the study carried out, It was observed that the number of picture taking station is more did not provide an important improvement in metric accuracy and, instead, it was concluded that picture taking geometry, which will cover the object to be measured in a good way, would be enough.
\end{abstract}

Keywords Non-metric Camera, Photogrammetry, Precision

\section{Introduction}

Photogrammetry is a scientific branch, which aims to preciously determine the shape of object in space, its dimensions, and position, utilizing one or few pictures. The general benefit of this technique that uses measurements carried out on the pictures is that it introduces a full image of the object in detail. Measurements of pictures became practical with the emergence of photography, which is an optical technical method, belonging to comprehensively forming the central perspective that fits to its origin. Photographic methods can be easily applied in the areas, where the other methods are not used.

\section{Orientation Processes at Photographic Evaluation}

In photographic evaluation, whichever method is used, it is necessary to make orientation processes. The process, in which the positions of pictures at the moment of taking picture are reobtained, is called orientation of pictures. It is carried out in two steps as internal orientation and external orientation. External orientation is carried out in two stages as opposing orientation and absolute orientation. In general, orientation processes are realized in three stages.

These are:

1. Internal orientation,

2. Opposing orientation, and

3. Absolute orientation.

\section{- Internal Orientation}

The process of internal orientation is generally expressed as bringing the features of taking camera to evaluation instrument. Internal orientation, carried out in the digital photogrammetric systems, is the introduction of camera information in the calibration to the system.

In other words, internal orientation step is the process of identifying the parameters of camera.

\section{- Opposing Orientation}

Removing the tilts and rotation of the picture by opposing orientation, picture pairs come to the position at the moment, which they are taken according to each other. Via opposing orientation, 3D model of the land or object is obtained. But this 3D model is not in parallel in land and scaled.

For being able to intersect of two footprint rays regarding the point $\mathrm{P}$, it is necessary for these two rays to be in the same plane. That these two rays are in the same plane is provided the condition of co-planarity.

Via opposing orientation, the positions and postures of beams obtained from both pictures to each other are arranged and it is enabled the rays coming from the congruent points in both pictures to intersect to each other. Via opposing orientation, a space model is obtained. At the end of this step, five independent out orientation elements $\left(\kappa_{1}, \kappa_{2}, \varphi_{1}, \varphi_{2}, \omega_{2}\right)$ is obtained.

\section{Absolute Orientation}

Just as the scale of space model obtained via opposing 
orientation is uncertain, its position and orientation in space are also uncertain. Bringing this model into the scale of desired model, it is necessary to shift and rotate it in such a way that coordinate values in land coordinate system belonging to that object will overlap with model coordinates. This is a three dimensional problem of similarity transformation. There are three $\operatorname{shifting}\left(\mathrm{X}_{0} \quad \mathrm{Y}_{0} \mathrm{Z}_{0}\right)$, three rotation $(\varphi \omega \kappa)$, and a scale $(\lambda)$ between two coordinate systems.

\section{Non-metric Digital Cameras}

In the recent times, the use of non-metric digital cameras in the topographic photogrammetry-aimed evaluation studies has considerably become widespread. That the prices of this kind of cameras are very low compared to topographic photogrammetry-aimed metric cameras attracts interest of users and they are widely used in many projects [1].

Although they are not produced for photogrammetric aims, digital cameras, which have a very intensive application compared to the film cameras, are used in photogrammetry as an instrument to obtain the strong and effective digital data [2].

Digital cameras are commonly used in the applications of close range photogrammetry and machine vision. Since they have the advantages of easiness of data storage, portability, and fast data processing, these cameras replaced with middle scaled film cameras in monitoring industry technology and structural movements

Many disciplines are using digital cameras and can present more effective and faster service to their users. Although they are not designed for photogrammetric aims, digital cameras are used as the instrument of obtaining data especially in close picture photogrammetry. Beside this, picture taking with aerial digital camera, which is in the test stage for the last 1-2 years, from now on, has begun to be presented for the use. Thus, in the stage of taking image with aerial photogrammetry, digital technology has been begun to be completely used [3].

It can be said that non-preventable errors, which will emerge in photographic material, do not affect measurement precision and that lens distortion is at negligible degree for schematic assessments, which will be made on analogue assessment instrument are the additional conditions for metric machines [4]. The machines, which do not have these features, are called non-metric picture taking machine.

When compared to the metric picture taking machines, the results met in non-metric picture taking machines can be put in order as irregular distortion, continuously change of internal orientation, lack of middle point finders, difficulty in orientating the picture taking machine to a certain direction, and lack of a specific equipment to enable film to be appropriate. In some machines, whose internal orientation is stable, by means of some extra equipment such as middle point finders, making adjustment as in metric machine, the ability to determine the elements of internal orientation is obtained However, these extra equipment increases the price of picture taking machine. In picture taking machines, whose internal orientation is not fixed, and which do not have middle point finders, adjustment process should be individually made by means of analytical method enabling to add unknown parameters of internal orientation elements by the mathematical model used.

\section{Internal Orientation Elements: \\ - Coordinates of Primary Points $\left(\mathrm{H}_{\mathrm{x}, \mathrm{y}}\right)$ \\ - Coordinates of footprint center $\left(\mathrm{X}_{0}, \mathrm{Y}_{0}, \mathrm{Z}_{0}\right)$ \\ - Focal length of camera}

That the qualified regions (depending on the values of focal length and diaphragm) of metric picture taking are restricted and their high prices prompted many users to find the way to utilize non-metric picture taking machines. Although very good results cannot be obtained with nonmetric picture taking machines used in the past, with initiating the studies for modification of non-metric machines used at the present days for these aims, very good results are found.

\section{Material and Method}

Topcon GPT 3007N Electronic Total Station (Figure 1), Paper Target (Figure 2), and non-metric camera (Figure 3), used in the study, were supplied.

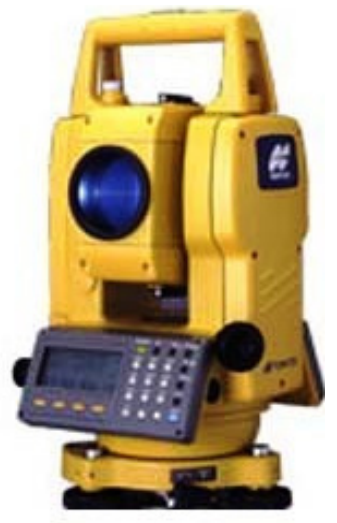

Figure 1. Total Station

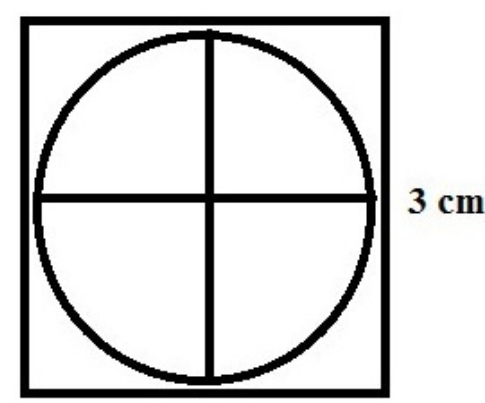

$3 \mathrm{~cm}$

Figure 2. Paper Target 


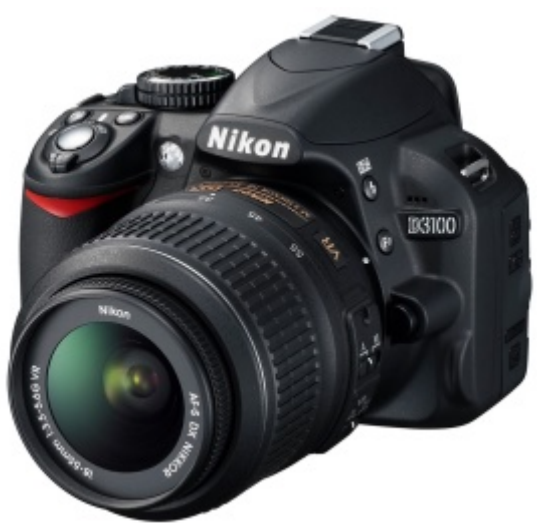

Figure 3. Nikon D3100

GPT-3007N series makes distance measure with single prism to $3000-3500 \mathrm{~m}$ and provides full precision $( \pm 2 \mathrm{~mm}$. + 2pPhotomodelerxD). GTS-3007N series completes the distance in the precise measurement mode (1 $\mathrm{mm}$ precision) in a short time like $1.2 \mathrm{~s}$ and makes record.

Technical properties of Nikon D3100, used in picture taking: Solubility, 14.2 MP; Sensor Dimension, 23.1x15.4 mm; Pixel Pitch, $5 \mu \mathrm{m}$; Pixel Area, $25 \mu \mathrm{m}^{2}$; Pixel Density, $3.99 \mathrm{MP} / \mathrm{cm}^{2}$.

\section{Study Area}

This study was carried out in Hadim Vocational High School. Selcuk University, Konya. In the study, 40 paper targets were used. The targets were installed in such a way that they will homogenously cover the study area.

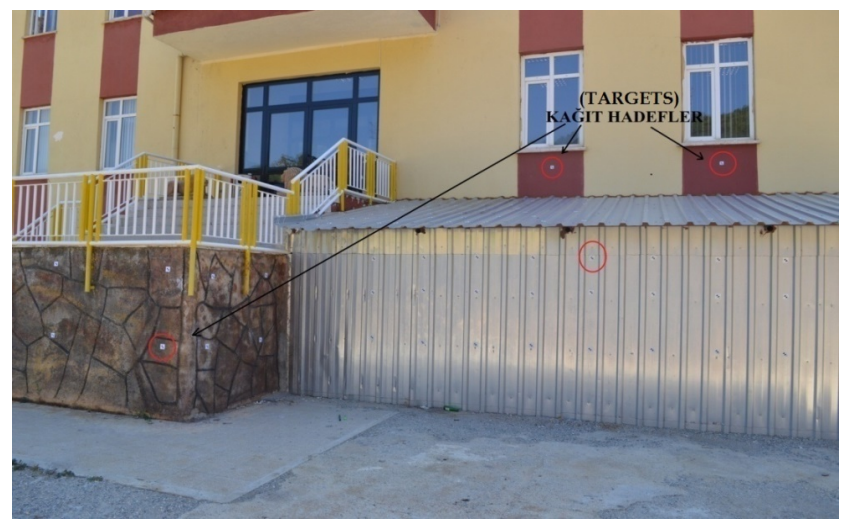

Figure 4. Installation of paper targets to the area

\section{Measurement and Photographing}

18 of these points installed has been used in the software of PhotoModeler as photographic evaluation-aimed, the remaining 22 points was utilized as control-aimed in the precision study of cameras. The process of coordinating these points was identified by the device of Topcon GPT $3007 \mathrm{~N}$ Electronic Total Station, whose precision is $2 \mathrm{~mm} \pm 2 \mathrm{p}$
Photomodeler in the local coordinate system.

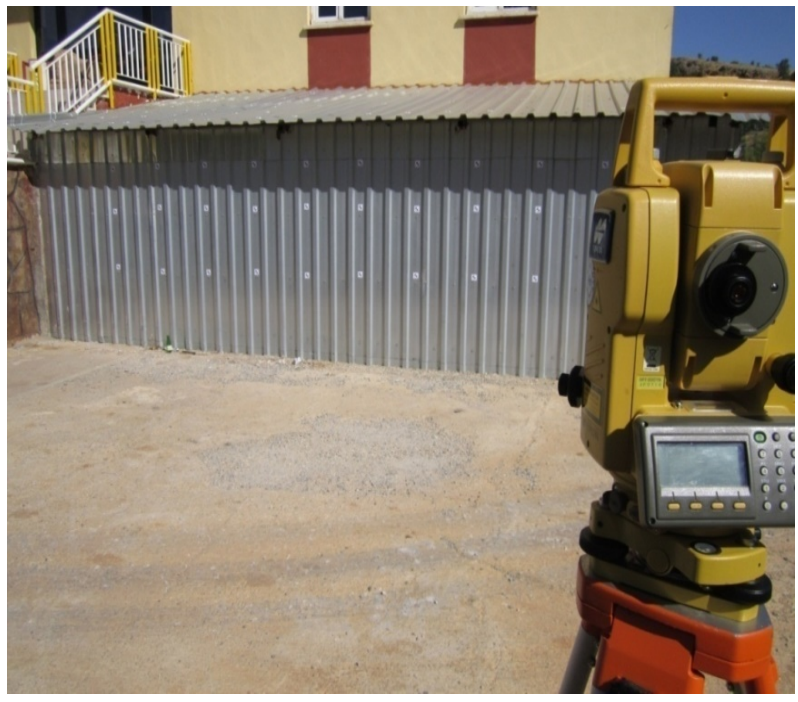

Figure 5. Measurement of Paper Targets

After the process of surveying the targets have been finished, the picture of test areas was taken according to convergent picture taking technique. In this process, keeping the distance between target object and picture taking station the same approximately, the effect of distance on mean square error was lowered to the negligible level.

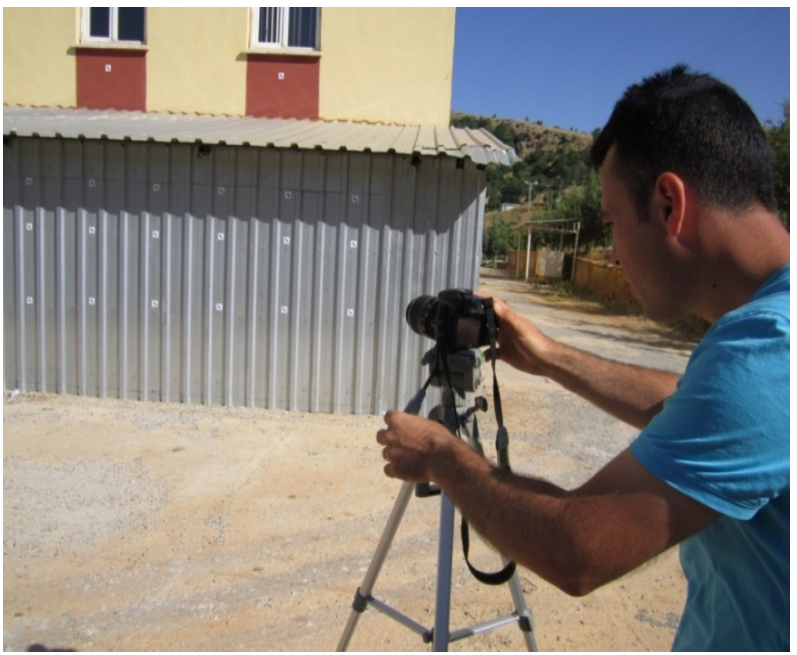

Figure 6. Process of photographing the target signs in the test area by the convergent picture taking method

Target signs in test area were first of all photographed by 3 picture taking station and then 6 picture taking station.

The coordinate lists of these photographs and control points were transferred to PhotoModeler software and passed to the process of photogrammetric evaluation for the comparison of cameras. For photogrammetric evaluation, by means of 18 control points, whose coordinates are calculated in PhotoModeler software, the pictures which will be used in precision study belonging to the test area were referenced, and balancing process was carried out.

For precision investigation, the coordinates of 22 control points installed in test area, obtained by Total Station device, 
were accepted as precise value. In PhotoModeler software, as a result of evaluation processes belonging to triplet and sestet taking picture stations, the coordinates of 22 control points were calculated and, among the coordinates accepted as precise value, taking their differences in the $\mathrm{x}$ and $\mathrm{y}$ axes, their weighted mean square errors were calculated. After completing the process of picture taking, the coordinates of the points obtained from the field and the differences of coordinates obtained through balanced pictures were also calculated. In this calculation, 22 pieces of point were used.
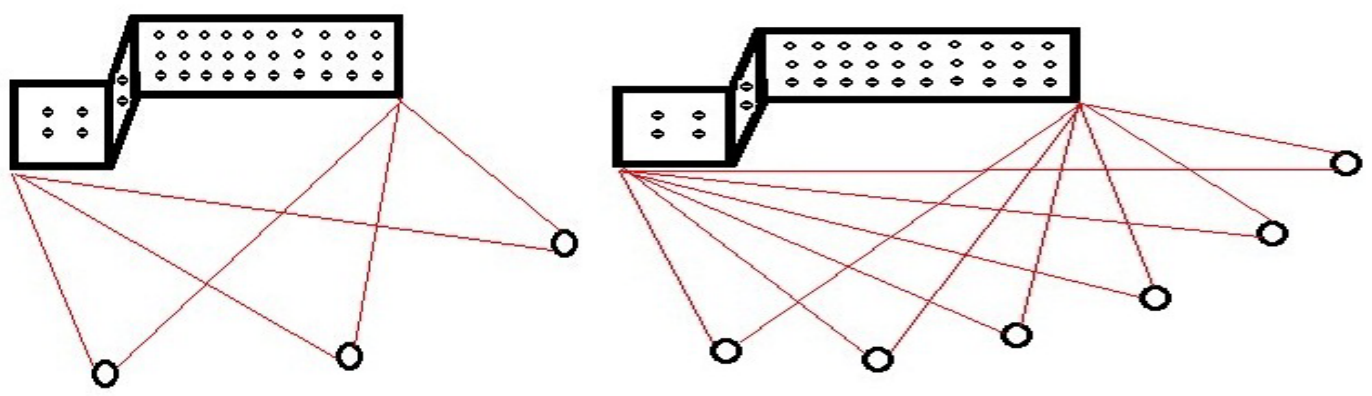

Figure 7. Triplet (left) or sestet (right) taking picture positions

Chart 1. The coordinates obtained from the precise, triplet and sestet convergent picture taking

\begin{tabular}{|c|c|c|c|c|c|c|c|c|c|}
\hline & \multicolumn{3}{|c|}{ CERTAIN COORDINATES } & \multicolumn{3}{|c|}{ TRIPLET STATION } & \multicolumn{3}{|c|}{ SESTET STATION } \\
\hline N.N. & $\mathrm{Y}(\mathrm{m})$ & $\mathrm{X}(\mathrm{m})$ & $\mathrm{Z}(\mathrm{m})$ & $\mathrm{Y}(\mathrm{m})$ & $\mathrm{X}(\mathrm{m})$ & $\mathrm{Z}(\mathrm{m})$ & $\mathrm{Y}(\mathrm{m})$ & $\mathrm{X}(\mathrm{m})$ & $\mathrm{Z}(\mathrm{m})$ \\
\hline 2 & 1006.280 & 1004.767 & 1001.462 & 1006.280 & 1004.767 & 1001.461 & 1006.282 & 1004.767 & 1001.461 \\
\hline 4 & 1006.225 & 1004.173 & 1001.890 & 1006.225 & 1004.172 & 1001.891 & 1006.226 & 1004.172 & 1001.891 \\
\hline 5 & 1006.228 & 1004.170 & 1001.505 & 1006.228 & 1004.170 & 1001.506 & 1006.228 & 1004.170 & 1001.505 \\
\hline 6 & 1006.235 & 1004.168 & 1000.890 & 1006.233 & 1004.167 & 1000.890 & 1006.232 & 1004.167 & 1000.889 \\
\hline 7 & 1006.182 & 1003.578 & 1001.899 & 1006.182 & 1003.578 & 1001.900 & 1006.184 & 1003.578 & 1001.901 \\
\hline 8 & 1006.186 & 1003.579 & 1001.504 & 1006.184 & 1003.579 & 1001.504 & 1006.185 & 1003.580 & 1001.504 \\
\hline 9 & 1006.188 & 1003.577 & 1000.901 & 1006.186 & 1003.577 & 1000.901 & 1006.187 & 1003.577 & 1000.900 \\
\hline 11 & 1006.138 & 1002.987 & 1001.501 & 1006.137 & 1002.987 & 1001.501 & 1006.137 & 1002.987 & 1001.501 \\
\hline 13 & 1006.090 & 1002.394 & 1001.903 & 1006.088 & 1002.394 & 1001.904 & 1006.090 & 1002.394 & 1001.905 \\
\hline 14 & 1006.090 & 1002.395 & 1001.532 & 1006.088 & 1002.395 & 1001.533 & 1006.087 & 1002.395 & 1001.532 \\
\hline 15 & 1006.089 & 1002.397 & 1000.915 & 1006.087 & 1002.397 & 1000.915 & 1006.089 & 1002.399 & 1000.916 \\
\hline 16 & 1006.044 & 1001.806 & 1001.912 & 1006.042 & 1001.806 & 1001.912 & 1006.043 & 1001.805 & 1001.913 \\
\hline 17 & 1006.041 & 1001.804 & 1001.531 & 1006.039 & 1001.803 & 1001.532 & 1006.042 & 1001.803 & 1001.533 \\
\hline 18 & 1006.037 & 1001.803 & 1000.945 & 1006.035 & 1001.803 & 1000.944 & 1006.035 & 1001.804 & 1000.944 \\
\hline 20 & 1005.992 & 1001.213 & 1001.526 & 1005.990 & 1001.213 & 1001.526 & 1005.989 & 1001.213 & 1001.526 \\
\hline 22 & 1005.945 & 1000.625 & 1001.904 & 1005.946 & 1000.623 & 1001.904 & 1005.944 & 1000.623 & 1001.903 \\
\hline 23 & 1005.944 & 1000.622 & 1001.537 & 1005.944 & 1000.620 & 1001.538 & 1005.944 & 1000.621 & 1001.537 \\
\hline 24 & 1005.943 & 1000.624 & 1000.963 & 1005.940 & 1000.623 & 1000.963 & 1005.940 & 1000.623 & 1000.963 \\
\hline 25 & 1005.898 & 1000.030 & 1001.900 & 1005.900 & 1000.028 & 1001.900 & 1005.900 & 1000.029 & 1001.900 \\
\hline 26 & 1005.900 & 1000.031 & 1001.536 & 1005.902 & 1000.030 & 1001.537 & 1005.902 & 1000.031 & 1001.538 \\
\hline 27 & 1005.898 & 1000.031 & 1000.973 & 1005.897 & 1000.033 & 1000.973 & 1005.897 & 1000.033 & 1000.974 \\
\hline 29 & 1005.860 & 999.438 & 1001.539 & 1005.861 & 999.436 & 1001.538 & 1005.861 & 999.437 & 1001.538 \\
\hline
\end{tabular}


Chart 2. The differences of the coordinates obtained from triplet and sestet picture taking from the precise coordinates

\begin{tabular}{|c|c|c|c|c|c|c|c|c|c|c|c|c|}
\hline & \multicolumn{6}{|c|}{ DIFFERENCES TRIPLET STATION } & \multicolumn{3}{|c|}{ DIFFERENCES SESTET STATION } & \multirow[b]{2}{*}{ VyVy } & \multirow[b]{2}{*}{$V x V x$} & \multirow[b]{2}{*}{$\mathrm{VzVz}$} \\
\hline N.N & $\mathrm{Vy}(\mathrm{mm})$ & $\mathrm{Vx}(\mathrm{mm})$ & $\mathrm{Vz}(\mathrm{mm})$ & $\mathrm{VyVy}$ & $\overline{V x V x}$ & $\mathrm{VzVz}$ & $\mathrm{Vy}(\mathrm{mm})$ & $\mathrm{Vx}(\mathrm{mm})$ & $\mathrm{Vz}(\mathrm{mm})$ & & & \\
\hline 2 & 0 & 0 & 1 & 0 & 0 & 1 & -2 & 0 & 1 & 4 & 0 & 1 \\
\hline 4 & 0 & 1 & -1 & 0 & 1 & 1 & -1 & 1 & -1 & 1 & 1 & 1 \\
\hline 5 & 0 & 0 & -1 & 0 & 0 & 1 & 0 & 0 & 0 & 0 & 0 & 0 \\
\hline 6 & 2 & 1 & 0 & 4 & 1 & 0 & 3 & 1 & 1 & 9 & 1 & 1 \\
\hline 7 & 0 & 0 & -1 & 0 & 0 & 1 & -2 & 0 & -2 & 4 & 0 & 4 \\
\hline 8 & 2 & 0 & 0 & 4 & 0 & 0 & 1 & -1 & 0 & 1 & 1 & 0 \\
\hline 9 & 2 & 0 & 0 & 4 & 0 & 0 & 1 & 0 & 1 & 1 & 0 & 1 \\
\hline 11 & 1 & 0 & 0 & 1 & 0 & 0 & 1 & 0 & 0 & 1 & 0 & 0 \\
\hline 13 & 2 & 0 & -1 & 4 & 0 & 1 & 0 & 0 & -2 & 0 & 0 & 4 \\
\hline 14 & 2 & 0 & -1 & 4 & 0 & 1 & 3 & 0 & 0 & 9 & 0 & 0 \\
\hline 15 & 2 & 0 & 0 & 4 & 0 & 0 & 0 & -2 & -1 & 0 & 4 & 1 \\
\hline 16 & 2 & 0 & 0 & 4 & 0 & 0 & 1 & 1 & -1 & 1 & 1 & 1 \\
\hline 17 & 2 & 1 & -1 & 4 & 1 & 1 & -1 & 1 & -2 & 1 & 1 & 4 \\
\hline 18 & 2 & 0 & 1 & 4 & 0 & 1 & 2 & -1 & 1 & 4 & 1 & 1 \\
\hline 20 & 2 & 0 & 0 & 4 & 0 & 0 & 3 & 0 & 0 & 9 & 0 & 0 \\
\hline 22 & -1 & 2 & 0 & 1 & 4 & 0 & 1 & 2 & 1 & 1 & 4 & 1 \\
\hline 23 & 0 & 2 & -1 & 0 & 4 & 1 & 0 & 1 & 0 & 0 & 1 & 0 \\
\hline 24 & 3 & 1 & 0 & 9 & 1 & 0 & 3 & 1 & 0 & 9 & 1 & 0 \\
\hline 25 & -2 & 2 & 0 & 4 & 4 & 0 & -2 & 1 & 0 & 4 & 1 & 0 \\
\hline 26 & -2 & 1 & -1 & 4 & 1 & 1 & -2 & 0 & -2 & 4 & 0 & 4 \\
\hline 27 & 1 & -2 & 0 & 1 & 4 & 0 & 1 & -2 & -1 & 1 & 4 & 1 \\
\hline 29 & -1 & 2 & 1 & 1 & 4 & 1 & -1 & 1 & 1 & 1 & 1 & 1 \\
\hline & & \multicolumn{2}{|c|}{$[\mathrm{VV}]$} & 61 & 25 & 11 & & \multicolumn{2}{|c|}{ [VV] } & 65 & 22 & 26 \\
\hline & & \multicolumn{2}{|c|}{$m= \pm \sqrt{\frac{[v \cdot v]}{n}}$} & 1.665 & 1.066 & 0.708 & & $m= \pm$ & $\frac{\overline{g \cdot v]}}{n}$ & 1.719 & 1.000 & 1.088 \\
\hline
\end{tabular}

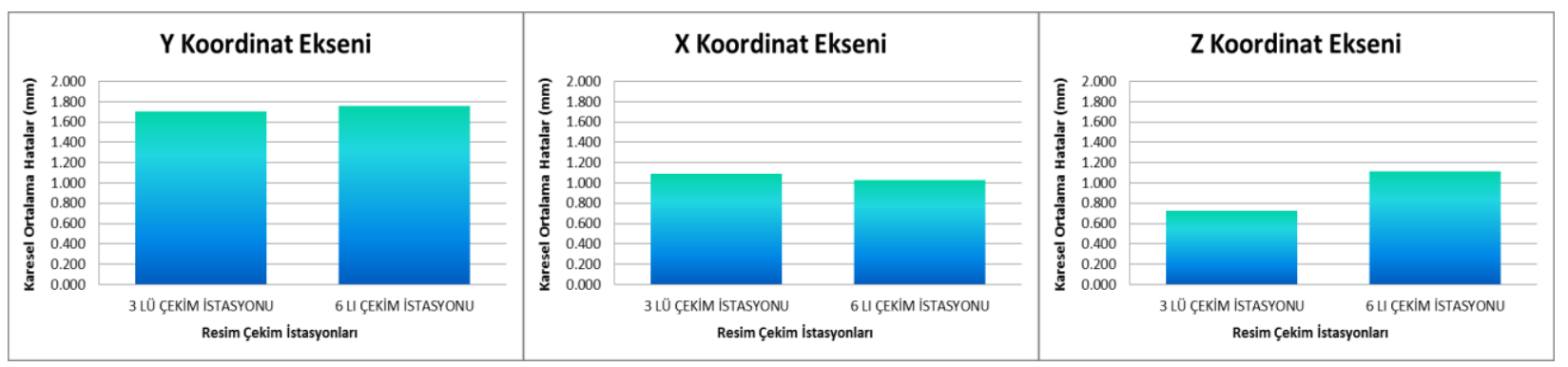

Graph 1. Graphs of mean square error in the axes X, Y, and Z

\section{Results}

As a result of the research, it is observed that surplus number of picture-taking stations does not make any significant progress in metric accuracy; instead, it is achieved that the shot geometry that will cover the object to be measured will be sufficient. With the evaluations carried out, it is seen that there is no important difference between the results obtained in the photogrammetric evaluations carried out 3 and 6 picture taking stations. As a result, in photogrammetric evaluation studies, keeping the number of picture taking station at the optimum level according to the quality of study carried out, it is necessary to pay attention to covering all of target object in the picture taken.

\section{Acknowledgments}

This study was prepared for Ali Ulvi's Doctorate thesis. 


\section{REFERENCES}

[1] Yildız F., Karabörk H., Yakar M., Y1lmaz H.Murat, Yersel Fotogrametride Kullanılan Metrik Olmayan Dijital Kameraların Kalibrasyonunda Kullanılan Yazılımların İncelenmesi Üzerine Bir Çalışma,2005

[2] Ahmad, A. ve Chandler, J.H., 1999. Photogrammetric Capabilities of the Kodak DC40, DCS420 and DCS460 Digital Cameras, Photogrammetric Record, 16(94), 601-615.

[3] Karslı F., E. Ayhan, Orta ve Yüksek Çözünürlüklü Dijital Kameraların Metrik Performanslarının Belirlenmesi,2005

[4] Toz,G.,1985.Yersel Fotogrametride Analog-Analitik ve Analitik Değerlendirme Yöntemlerinin Yap1 Konstrüksiyon Deneylerinde Uygulama Olanakları, Doktora Tezi, Fen Bilimleri Enstitüsü, İstanbul 